\title{
Insulin-like growth factor 1 receptor expression in breast cancer tissue and mammographic density
}

\author{
WOO-YOUNG SUN ${ }^{1}$, HYO-YOUNG YUN ${ }^{2}$, YOUNG-JIN SONG ${ }^{2}$, HEON KIM ${ }^{3}$, \\ OK-JUN LEE ${ }^{4}$, SEOK-JIN NAM ${ }^{5}$ and JA-SEUNG KOO ${ }^{6}$
}

\begin{abstract}
${ }^{1}$ Department of Surgery, Daejeon St. Mary's Hospital, The Catholic University of Korea College of Medicine, Daejeon 301-723; Departments of ${ }^{2}$ Surgery, ${ }^{3}$ Preventive Medicine and ${ }^{4}$ Pathology, Chungbuk National University College of Medicine and Medical Research Institute, Cheongju, Chungcheong 361-763; ${ }^{5}$ Department of Surgery, Samsung Medical Center, Seoul 135-710; ${ }^{6}$ Department of Pathology, Severance Hospital, Yonsei University College of Medicine, Seoul 120-752, Republic of Korea
\end{abstract}

Received February 11, 2014; Accepted January 16, 2015

DOI: $10.3892 / \mathrm{mco} .2015 .497$

\begin{abstract}
The aim of this study was to evaluate the association between insulin-like growth factor 1 receptor (IGF-1R) expression in breast cancer tissue and mammographic density and the clinical significance of IGF-1R overexpression. A total of 167 patients with primary invasive breast cancer were analyzed. Mammographic breast density and IGF-1R overexpression were correlated with clinicopathological parameters and analyzed by overall survival (OS) and disease-free survival (DFS). Increased breast tissue density was significantly associated with age, body mass index, menopausal status, histological grade and IGF-1R overexpression in the univariate analysis and with age $(\mathrm{P}=0.001)$, histological grade $(\mathrm{P}=0.045)$ and IGF-1R overexpression $(\mathrm{P}=0.021)$ in the multivariate analysis. IGF-1R overexpression was significantly associated with dense breast tissue in patients aged $>40$ years $(\mathrm{P}=0.002)$. IGF-1R overexpression in breast cancer in premenopausal women was associated with human epidermal growth factor receptor 2 (HER-2) positivity $(\mathrm{P}=0.016)$ and worse DFS $(\mathrm{P}=0.0414)$. There was no significant difference in OS and DFS between dense and non-dense breast tissue. IGF-1R expression in breast cancer tissue was significantly associated with mammographic breast tissue density in patients aged $>40$ years. It appears that IGF-1R expression in breast cancer tissue plays an important role in breast cancer in patients with dense breast tissue. In premenopausal women, IGF-1R overexpression in breast cancer tissue was significantly associated with HER-2 positivity and poor DFS.
\end{abstract}

Correspondence to: Professor Young-Jin Song, Department of Surgery, Chungbuk National University College of Medicine and Medical Research Institute, 410 Seongbong-ro, Cheongju, Chungcheong 361-763, Republic of Korea

E-mail: yjsong@chungbuk.ac.kr

Key words: mammography, density, insulin-like growth factor 1 receptor, breast neoplasm, immunohistochemistry

\section{Introduction}

Due to the growing public interest in breast cancer and the widespread use of mammographic screening, the early detection rate of breast cancer has increased. Increased breast tissue density, however, may make mammograms more difficult to interpret. Dense breast tissue is considered one of the major risk factors of breast cancer, although the underlying mechanism has yet to be elucidated (1). Mammographic breast density refers to the percentage of fibroglandular tissues in the breast. The incidence of breast cancer was found to be 4-6-fold higher in a group with higher breast density compared to that in another, lower density group $(2,3)$.

As a factor associated with mammographic breast density, the insulin-like growth factor (IGF) system has been well documented and reported to be of more relevance to premenopausal women $(4,5)$. The IGF system acts as a factor controlling growth in the human body and plays an important role in the development of normal breast tissues. The IGF system consists of IGF-1, IGF-2, IGF-1 receptor (IGF-1R), IGF-2R and six IGF-binding proteins (IGFBPs) (6). Notably, IGF-1 and IGFBP in the blood are reported to affect breast density. Normal dense breast tissues exhibit a higher expression of IGF-1 compared to non-dense breast tissue, which suggests that IGF-1 is associated with mammographic density (7). However, rather than observing the IGF-1 expression in tissues, examining the expression of receptors and downstream signaling molecules activated by these receptors may provide more accurate information on its relevance to breast tissue density. To the best of our knowledge, no previous studies have investigated the relevance of IGF-1R expression in breast cancer tissues to breast density. By investigating the correlation between mammographic density and IGF-1R expression, we may determine whether IGF-1R expression is associated with the mechanism underlying dense breast tissue constituting a risk factor for breast cancer.

In terms of its structure, IGF-1R is similar to insulin receptors and consists of an $\alpha$ chain that has two extracellular binding domains and two transmembrane $\beta$ chains, forming a heterodimer. IGF-1R is a transmembrane tyrosine kinase 
receptor and its expression is known to be involved in mitosis, advancement and metastasis of breast cancer $(8,9)$. Unlike other tyrosine kinase receptors, IGF-1R is subject to autocrine, paracrine and endocrine controls (10). In normal breast epithelial tissues, IGF-1R reportedly exhibits a homogenous moderate expression. Although IGF-1R expression in breast cancer has been limitedly investigated, its overexpression in tumour tissues shows a wide distribution, namely $39-93 \%(11,12)$. The overexpression of IGF-1R promotes anti-apoptosis, cell adhesion, mitosis and malignant cell transformation, resulting in breast cancer (12-14). Although certain studies reported that the overexpression of IGF-1R in breast cancer is closely associated with estrogen receptors (ERs) and serves as a good prognostic factor, other studies reported conflicting results; thus, the findings on the clinical significance of IGF-1R overexpression in tumours are not consistent across studies (15-18).

The present study aimed to investigate the correlations between IGF-1R expression in breast cancer tissues, mammographic density and other clinicopathological factors and determine the clinical significance of IGF-1R overexpression.

\section{Patients and methods}

Patients. A total of 167 breast cancer patients (median age 47years; range, 20-81 years) who were operated at the Department of Surgery of Severance Hospital between January, 2000 and December, 2001 were analyzed. Patient information, including age, height, weight, menopausal status, medication history, survival and recurrence status and clinicopathological data, including tumour size, nuclear grade, histological grade and lymph node metastasis, were obtained from electronic medical records. The mean follow-up was 91 months (range, 5-115 months). Mammographic breast density and IGF-1R overexpression were correlated with clinicopathological parameters and analyzed by overall survival (OS) and disease-free survival (DFS). This study conformed to the guidelines of the local Ethics Committee.

Immunohistochemical (IHC) analysis. Serial 4- $\mu$ m sections of the tissue microarray block, containing breast cancer tissue with a diameter of $3 \mathrm{~mm}$, were mounted on electrostatic slides, heat-dried at $56^{\circ} \mathrm{C}$ for $30 \mathrm{~min}$, deparaffinized in xylene and rehydrated through graded concentrations of ethanol. The slides were incubated in a solution of $3 \%$ hydrogen peroxide in methanol for 15 min to block endogenous peroxidase activity. The slides were incubated in $0.3 \%$ bovine serum albumin/1X Tris-buffered saline (TBS) for $20 \mathrm{~min}$ to reduce non-specific background staining. A primary antibody was applied for $30 \mathrm{~min}$ at room temperature. After a series of TBS rinses, the bound antibody was detected using a polymer secondary antibody from the Dako EnVision+ system (Dako, Carpinteria, CA, USA). The slides were rinsed with a TBS series and visualized after a 10-min incubation of liquid 3,3'-diaminobenzidine (DAB) in buffered substrate (Dako) for $10 \mathrm{~min}$. The slides were counterstained with hematoxylin. IHC analysis for rabbit anti-ER antibody (RM-9101; SP1, 1:100; Thermo Scientific, San Diego, CA, USA), mouse anti-progesterone receptor (PR) antibody (M3569; PgR, 1:50; DakoCytomation, Glostrup, Denmark), rabbit human epidermal growth factor receptor 2 (HER-2) antibody (A0485; polyclonal, 1:1,500; DakoCytomation), mouse epidermal growth factor receptor (EGFR) antibody (NCL-EGFR-384; EGFR 25, 1:50; Novocastra, Newcastle, UK), mouse cytokeratins (CK) 5/6 antibody (M7237; D5/16B4, 1:100; DakoCytomation), mouse Ki-67 antibody (M7240; MIB-1, 1:10; DakoCytomation). For IHC staining of rabbit IGF-1R antibody (3027), tissue sections were cut and placed on Superfrost Plus microscope slides (Fisher Scientific, San Diego, CA, USA). Using the Benchmark XT automated IHC stainer (IR $\beta, 1: 10$; Cell Signaling Technology, Inc., Danvers, MA, USA), the slides were stained. The sections were deparaffinized using EZ Prep solution. $\mathrm{CC} 1$ standard (a pH 8.4 buffer containing Tris/Borate/EDTA) was used for antigen retrieval. DAB inhibitor $\left(3 \% \mathrm{H}_{2} \mathrm{O}_{2}\right.$; endogenous peroxidase) was blocked for $4 \mathrm{~min}$ at $37^{\circ} \mathrm{C}$ temperature. The slides were incubated with antibodies for $40 \mathrm{~min}$ at $37^{\circ} \mathrm{C}$ and a secondary antibody of Univeral HRP Multimer for $8 \mathrm{~min}$ at $37^{\circ} \mathrm{C}$. The slides were then treated with $\mathrm{DAB}+\mathrm{H}_{2} \mathrm{O}_{2}$ substrate for $8 \mathrm{~min}$, followed by hematoxylin and bluing reagent counterstain at $37^{\circ} \mathrm{C}$. Reaction buffer (pH 7.6 Tris buffer) was used as a washing solution. Detection was performed using the Ventana Ultraview DAB kit (Ventana Medical Systems, Inc., Tucson, AZ, USA).

Interpretation of IHC staining. All IHC markers were evaluated by light microscopy. The immunostained slides were scored according to the percentage of tumour cells exhibiting nuclear (ER, PR), cytoplasmic (CK 5/6) and membranous (HER-2, EGFR) staining. A cut-off value of $\geq 1 \%$ positively stained nuclei was used to define ER and PR positivity. HER-2 staining was analyzed as follows: 0, no immunostaining; 1+, weak incomplete membranous staining, $<10 \%$ of the tumour cells; $2+$, complete membranous staining, either uniform or weak in $\geq 10 \%$ of the tumour cells; and $3+$, uniform intense membranous staining in $\geq 30 \%$ of the tumour cells. HER-2 immunostaining was considered to be positive when strong $(3+)$ membranous staining was observed, whereas cases scored as 0 or $1+$ were considered to be negative. The cases exhibiting 2+ HER-2 expression were evaluated for HER-2 amplification by fluorescent in situ hybridization (FISH). The IGF-1R expression was scored according to the intensity of the membranous staining within the invasive component in accordance with the scoring of HER-2 by the HercepTest: 0 , no staining or staining observed in $<10 \%$ of the tumour cells; $1+$, faint or barely perceptible membranous staining in $\geq 10 \%$ of the tumour cells and cells only stained in part of their membrane; $2+$, weak to moderate complete membranous staining in $\geq 10 \%$ of the tumour cells; and $3+$, strong complete membranous staining in $\geq 10 \%$ of the tumour cells (15). According to the IGF-1R expression, the cases were divided into low-expression (scores 0 and 1) and overexpression groups (scores 2 and 3) (Fig. 1).

Tumour subtype classification. Breast cancer subtypes were classified according to the IHC and FISH results for ER, PR and HER-2 as follows: Luminal A type, ER- or/and PR-positive and HER-2-negative; luminal B type, ER- or/and PR-positive and HER-2 overexpressed or/and amplified; HER-2 type, ER- and PR-negative and HER-2 overexpressed or/and amplified; triple-negative breast cancer type, ER-, PR-and HER-2 negative. 


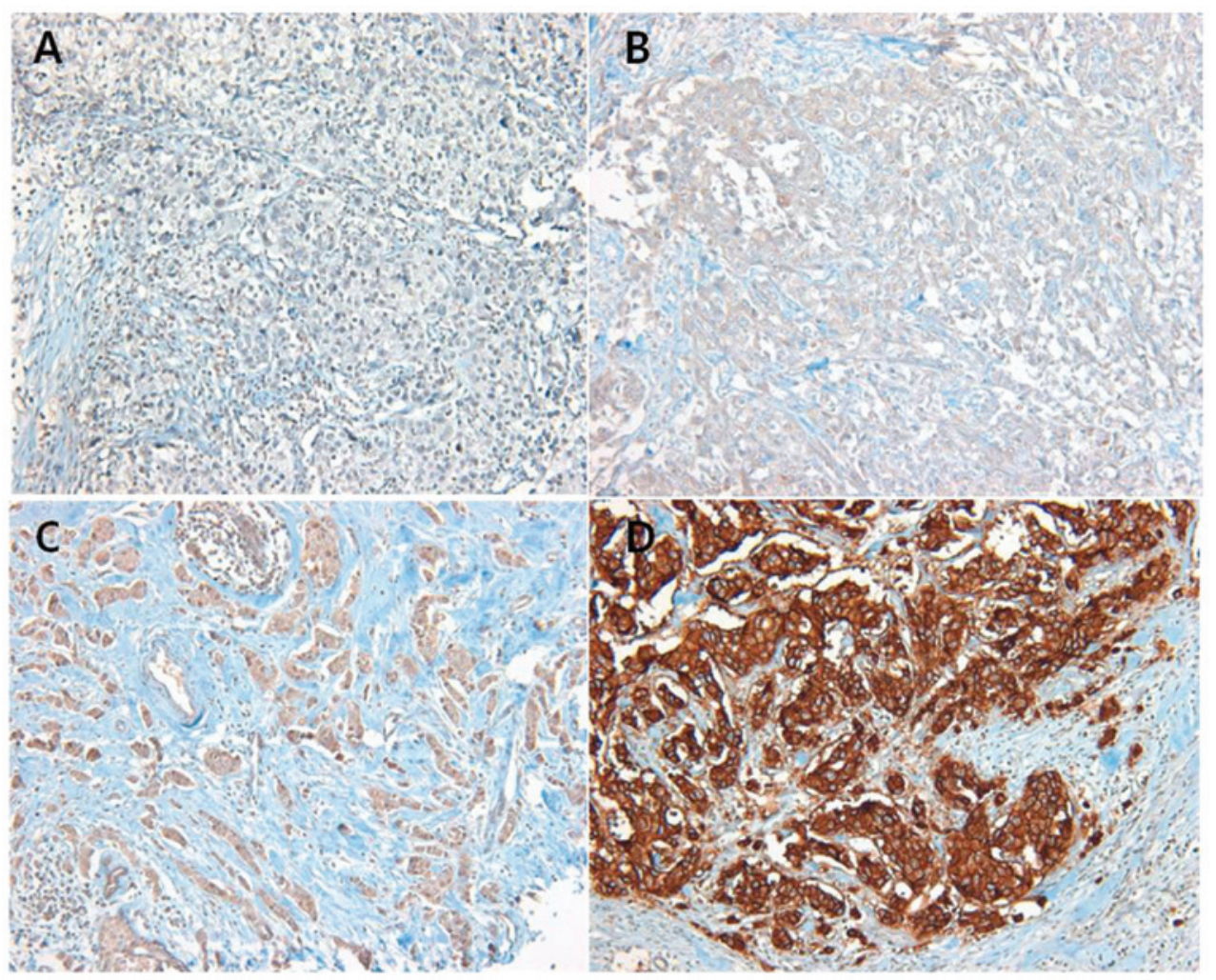

Figure 1. Immunohistochemical findings of insulin-like growth factor 1 receptor (IGF-1R) expression. IGF-1R expression was scored according to area and intensity of membranous staining. (A) score 0; (B) score 1; (C) score 2; and (D) score 3. Magnification, x100.

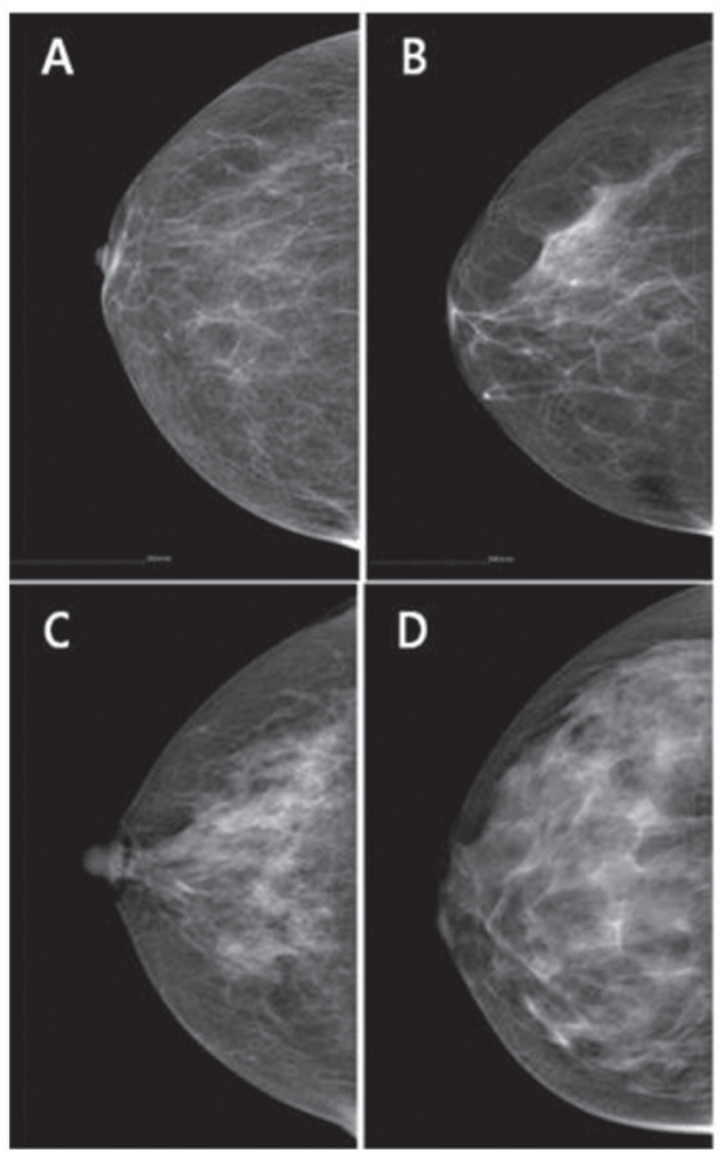

Figure 2. Mammographic breast density. Mammographic breast density is an estimate of the extent of fibroglandular tissue in relation to fat. (A) $0-25 \%$ (B) $26-50 \%$; (C) $51-75 \%$; (D) $76-100 \%$.
Mammographic density. The mammographic images taken at the time of operation or within 1 year after the operation were evaluated. All the mammograms were performed in the same clinic with the Lorad M-III unit (Lorad Medical Systems, Danbury, CT, USA) and were reviewed by one radiologist and one breast surgeon with experience in the assessment of breast density by visual grading system. On the basis of American College of Radiology Breast Imaging Reporting and Data System (BI-RADS) breast composition, four density patterns were designated as grades 1-4, with dense breast tissue graded as 3 and 4 (Fig. 2). The inter-observer variability of the mammographic density was 0.679 and the intra-observer variability was 0.786 and 0.703 , respectively.

Statistical analysis. Data were processed using SPSS software for Windows, version 12.0 (SPSS Inc., Chicago, IL, USA). The Chi-square test for univariate analysis and the logistic regression analysis for multivariate analysis were used to assess the correlation among IGF-1R expression, mammographic breast density, clinicopathological variables and breast cancer-related biomarkers. Cohen's Kappa test was used to assess intra- and inter-observer variability in the evaluation of mammographic breast density. Kaplan-Meier survival curves were employed to evaluate OS and DFS. The Chi-square test was used for univariate analysis and multivariate regression analysis was performed using the Cox proportional hazards model, with variables including mammographic breast density, expression of IGF-1R, nuclear grade, histological grade, tumour size, lymph node metastasis, ER, PR and HER-2 status, EGFR, CK 5/6 and Ki-67 for survival analysis. $\mathrm{P}<0.05$ was considered to indicate a statistically significant difference. 
Table I. Correlation of insulin-like growth factor 1 receptor (IGF-1R) expression and mammographic breast density with clinicopathological variables in primary breast cancer.

\begin{tabular}{|c|c|c|c|c|c|c|c|}
\hline \multirow[b]{3}{*}{ Variables } & \multirow[b]{3}{*}{ Total (\%) } & \multicolumn{3}{|c|}{ IGF-1R expression } & \multicolumn{3}{|c|}{ Dense breast tissue } \\
\hline & & Low & \multicolumn{2}{|l|}{ High } & \multirow{2}{*}{$\begin{array}{l}\text { Negative } \\
\text { No. }(\%)\end{array}$} & \multicolumn{2}{|l|}{ Positive } \\
\hline & & No. $(\%)$ & No. $(\%)$ & P-value & & No. $(\%)$ & P-value \\
\hline \multicolumn{8}{|l|}{ Age, years } \\
\hline Median, 47 (range, 20-81) & 167 & $104(62.3)$ & $63(37.7)$ & 0.207 & $97(58.1)$ & $70(41.9)$ & 0.001 \\
\hline \multicolumn{8}{|l|}{ Menopausal status } \\
\hline Premenopausal & $98(58.7)$ & $59(56.7)$ & $39(61.9)$ & \multirow[t]{2}{*}{0.338} & $50(51.5)$ & $48(68.6)$ & \multirow[t]{2}{*}{0.889} \\
\hline Postmenopausal & $69(41.3)$ & $45(43.3)$ & $24(38.1)$ & & $47(48.5)$ & $22(31.4)$ & \\
\hline \multicolumn{8}{|l|}{ BMI } \\
\hline$<23$ & $70(41.9)$ & $44(42.3)$ & $26(41.3)$ & \multirow[t]{2}{*}{0.312} & $33(34.0)$ & $37(52.9)$ & \multirow[t]{2}{*}{0.093} \\
\hline$\geq 23$ & $97(58.1)$ & $60(57.7)$ & $37(58.7)$ & & $64(66.0)$ & $33(47.1)$ & \\
\hline \multicolumn{8}{|l|}{ Nuclear grade } \\
\hline 1 & $10(6.0)$ & $6(5.8)$ & $4(6.3)$ & \multirow[t]{3}{*}{0.147} & $6(6.2)$ & $4(5.7)$ & \multirow[t]{3}{*}{0.218} \\
\hline 2 & $99(59.3)$ & $65(62.5)$ & $34(54.0)$ & & $63(64.9)$ & $36(51.4)$ & \\
\hline 3 & $58(34.7)$ & $33(31.7)$ & $25(39.7)$ & & $28(28.9)$ & $30(42.9)$ & \\
\hline \multicolumn{8}{|l|}{ Histological grade } \\
\hline 1 & $28(16.8)$ & $18(17.3)$ & $10(15.9)$ & \multirow[t]{3}{*}{0.357} & $23(23.8)$ & $5(7.1)$ & \multirow[t]{3}{*}{0.045} \\
\hline 2 & $88(52.7)$ & $53(51.0)$ & $35(55.5)$ & & $50(51.5)$ & $38(54.3)$ & \\
\hline 3 & $51(30.5)$ & $33(31.7)$ & $18(28.6)$ & & $24(24.7)$ & $27(38.6)$ & \\
\hline \multicolumn{8}{|l|}{ Tumor size } \\
\hline $\mathrm{T} 1$ & $66(39.5)$ & $37(35.6)$ & $29(46.0)$ & \multirow[t]{3}{*}{0.145} & $43(44.3)$ & $23(32.8)$ & \multirow[t]{3}{*}{0.828} \\
\hline $\mathrm{T} 2$ & $97(58.1)$ & $65(62.5)$ & $32(50.8)$ & & $52(53.6)$ & $45(64.3)$ & \\
\hline $\mathrm{T} 3$ & $4(2.4)$ & $2(1.9)$ & $2(3.2)$ & & $2(2.1)$ & $2(2.9)$ & \\
\hline \multicolumn{8}{|l|}{ Lymph node metastasis } \\
\hline N0 & $92(55.1)$ & $58(55.7)$ & $34(54.0)$ & \multirow[t]{4}{*}{0.782} & $60(61.9)$ & $32(45.7)$ & 0.193 \\
\hline N1 & $44(26.3)$ & $29(27.9)$ & $15(23.8)$ & & $23(23.7)$ & $21(30.0)$ & \\
\hline $\mathrm{N} 2$ & $20(12.0)$ & $11(10.6)$ & $9(14.3)$ & & $10(10.3)$ & $10(14.3)$ & \\
\hline N3 & $11(6.6)$ & $6(5.8)$ & $5(7.9)$ & & $4(4.1)$ & $7(10.0)$ & \\
\hline Subtype & & & & & & & \\
\hline Luminal A & $86(51.5)$ & $50(48.1)$ & $36(57.1)$ & 0.670 & $51(52.6)$ & $35(50.0)$ & 0.842 \\
\hline Luminal B & $21(12.6)$ & $12(11.5)$ & $9(14.3)$ & & $14(14.4)$ & $7(10.0)$ & \\
\hline HER-2 & $24(14.4)$ & $19(18.3)$ & $5(7.9$ & & $11(11.3)$ & 13 (18.6) & \\
\hline TNBC & $36(21.5)$ & $23(22.1)$ & $13(20.7$ & & $21(21.7)$ & $15(21.4)$ & \\
\hline IGF-1R expression & & & & & & & \\
\hline Low $(0,1)$ & $104(62.3)$ & $104(100.0)$ & $0(0.0)$ & & $68(70.1)$ & $36(51.4)$ & 0.021 \\
\hline $\operatorname{High}(2,3)$ & $63(37.7)$ & $0(0.0)$ & $63(100.0)$ & & $29(29.9)$ & $34(48.6)$ & \\
\hline Dense breast tissue & & & & & & & \\
\hline Negative & $97(58.1)$ & $68(65.4)$ & $29(46.0)$ & 0.021 & $97(100.0)$ & $0(0.0)$ & \\
\hline Positive & $70(41.9)$ & $36(34.6)$ & $34(54.0)$ & & $0(0.0)$ & $70(100.0)$ & \\
\hline
\end{tabular}

BMI, body mass index; HER-2, human epidermal growth factor receptor 2; TNBC, triple-negative breast cancer.

\section{Results}

Correlation of clinicopathological characteristics with $I G F-1 R$ expression and mammographic density. The clinicopathological characteristics of the patients and the correlation among IGF-1R expression, mammographic breast density, clinicopathological variables and breast cancer-related biomarkers are shown in Tables I and II.

The density patterns on mammography were non-dense breast tissue (grades 1 and 2) in 97 patients (58.1\%) and dense breast tissue in 70 patients $(41.9 \%)$. The frequency of dense breast tissue according to age was $100 \%$ (20-29 years), $70 \%$ 
Table II. Correlation of insulin-like growth factor 1 receptor (IGF-1R) expression and mammographic breast density with breast cancer-related biomarkers.

\begin{tabular}{|c|c|c|c|c|c|c|c|}
\hline \multirow[b]{3}{*}{ Biomarkers } & \multirow[b]{3}{*}{$\begin{array}{l}\text { Total }(\%) \\
(\mathrm{n}=167)\end{array}$} & \multicolumn{3}{|c|}{ IGF-1R expression } & \multicolumn{3}{|c|}{ Dense breast tissue } \\
\hline & & Low & High & & Negative & Positive & \\
\hline & & $\begin{array}{l}\text { No. }(\%) \\
(n=104)\end{array}$ & $\begin{array}{c}\text { No. }(\%) \\
(n=63)\end{array}$ & P-value & $\begin{array}{l}\text { No. }(\%) \\
(\mathrm{n}=97)\end{array}$ & $\begin{array}{c}\text { No. }(\%) \\
(n=70)\end{array}$ & P-value \\
\hline \multicolumn{8}{|l|}{ ER } \\
\hline Negative & $63(37.7)$ & $44(42.3)$ & $19(30.2)$ & 0.301 & $34(35.1)$ & $29(41.4)$ & 0.855 \\
\hline Positive & $104(62.3)$ & $60(57.7)$ & $44(69.8)$ & & $63(64.9)$ & $41(58.6)$ & \\
\hline \multicolumn{8}{|l|}{ PR } \\
\hline Negative & $95(56.9)$ & $62(59.6)$ & $33(52.4)$ & 0.845 & $49(50.5)$ & $46(65.7)$ & 0.059 \\
\hline Positive & $72(43.1)$ & $42(40.4)$ & 30 (47.6) & & $48(49.5)$ & $24(34.3)$ & \\
\hline \multicolumn{8}{|l|}{ HER-2 } \\
\hline Negative & $122(73.1)$ & $73(70.2)$ & $49(77.8)$ & 0.215 & $72(74.2)$ & $50(71.4)$ & 0.405 \\
\hline Positive & 45 (26.9) & 31 (29.8) & $14(22.2)$ & & $25(25.8)$ & $20(28.6)$ & \\
\hline \multicolumn{8}{|l|}{ EGFR } \\
\hline Negative & $141(84.4)$ & $86(82.7)$ & $55(87.3)$ & 0.980 & $83(85.6)$ & $58(82.9)$ & 0.958 \\
\hline Positive & $26(15.6)$ & $18(17.3)$ & 8 (12.7) & & $14(14.4)$ & $12(17.1)$ & \\
\hline \multicolumn{8}{|l|}{ CK 5/6 } \\
\hline Negative & $156(93.4)$ & $97(93.3)$ & $59(93.7)$ & 0.812 & $90(92.8)$ & $66(94.3)$ & 0.194 \\
\hline Positive & $11(6.6)$ & 7 (6.7) & $4(6.3)$ & & $7(7.2)$ & $4(5.7)$ & \\
\hline \multicolumn{8}{|l|}{ Ki-67 } \\
\hline Low, $<10 \%$ & $123(73.7)$ & $72(69.2)$ & $51(81.0)$ & 0.160 & $73(75.3)$ & $50(71.4)$ & 0.947 \\
\hline High, $\geq 10 \%$ & $44(26.3)$ & $32(30.8)$ & $12(19.0)$ & & $24(24.7)$ & $20(28.6)$ & \\
\hline
\end{tabular}

ER, estrogen receptor; PR, progesterone receptor; HER-2, human epidermal growth factor receptor 2; EGFR, epidermal growth factor receptor; CK, cytokeratin.

(30-39 years), $40.3 \%$ (40-49 years), $43.8 \%$ (50-59 years), $10.6 \%$ (60-69 years) and 0\% (70-89 years) (data not shown). Dense breast tissue was significantly associated with age, body mass index (BMI), menopausal status, histological grade and IGF-1R overexpression in the univariate analysis and with age $(\mathrm{P}=0.001)$, histological grade $(\mathrm{P}=0.045)$ and IGF-1R overexpression $(\mathrm{P}=0.021)$ in the multivariate analysis (Tables I and II).

IGF-1R expression was scored as 0 in 34 patients $(20.4 \%)$, 1 in 70 patients $(41.9 \%), 2$ in 60 patients $(35.9 \%)$ and 3 in 3 patients $(1.8 \%)$. The frequency of IGF-1R overexpression according to age was 0\% (20-29 years), 34.5\% (30-39 years), $45.2 \%$ (40-49 years), $37.8 \%$ (50-59 years), 31.6\% (60-69 years), $16.7 \%$ (70-79 years) and 0\% (80-89 years) (data not shown). IGF-1R overexpression was significantly associated with dense breast tissue at ages $>40$ years $(\mathrm{P}=0.002)$. Overexpression of IGF-1R was identified in 63 patients (37.7\%), but exhibited no correlation with any clinicopathological parameters, such as age, BMI, primary tumour size, nuclear grade, histological grade, lymph node metastasis, ER, PR, HER-2, EGFR and Ki-67 (Tables I and II).

ER expression $(\mathrm{P}=0.010$, odds ratio $=0.516)$ was associated with DFS and nuclear grade $(\mathrm{P}=0.029$, odds ratio=0.068), histologic grade $(\mathrm{P}=0.019$, odds ratio $=16.318)$, lymph node metastasis
$(\mathrm{P}=0.014$, odds ratio=3.140) and $\mathrm{ER}$ expression $(\mathrm{P}=0.016$, odds ratio $=0.041)$ were associated with OS (Table III). There was no significant difference in OS and DFS between dense and non-dense breast tissue (Fig. 3). IGF-1R overexpression in breast cancer in premenopausal women was associated with HER-2 positivity ( $\mathrm{P} \sim 0.016)$ and worse DFS ( $\mathrm{P}=0.0414)$ (Fig. 4).

\section{Discussion}

The earlier detection rate of breast cancer is continuously increasing, as a result of the growing public interest in breast cancer and the wider application of selective mammographic screening. However, increased breast density makes it more difficult to detect tumours in women exhibiting dense breast tissue on mammography; in addition, the presence of dense breast tissue per se is known to be associated with an increased risk of breast cancer. It was reported that alternative hormonal therapy, particularly estrogen-progestin complex therapy, increased the frequency of dense breast tissue and, thus, the risk of breast cancer (19). The administration of hormonal inhibitors, such as tamoxifen, decreased the recurrence rates of breast cancer as well as breast tissue density, further suggesting that increased breast tissue density constitutes a risk factor for breast cancer (20). 
Table III. Cox's proportional hazards regression models for overall survival (OS) and disease-free survival (DFS).

\begin{tabular}{|c|c|c|c|c|c|c|c|}
\hline \multirow[b]{2}{*}{ Variables } & \multirow[b]{2}{*}{ No. } & \multicolumn{3}{|c|}{ OS } & \multicolumn{3}{|c|}{ DFS } \\
\hline & & $\mathrm{RR}$ & $95 \% \mathrm{CI}$ & P-value & $\mathrm{RR}$ & $95 \% \mathrm{CI}$ & P-value \\
\hline \multicolumn{8}{|c|}{ Dense breast tissue } \\
\hline Negative & 97 & 0.647 & $0.138-3.424$ & 0.647 & 1.175 & $0.816-1.692$ & 0.387 \\
\hline Positive & 70 & & & & & & \\
\hline \multicolumn{8}{|l|}{ Nuclear grade } \\
\hline 1 & 10 & 0.068 & $0.006-0.759$ & 0.029 & 1.086 & 0.694-1.699 & 0.719 \\
\hline 2 & 99 & & & & & & \\
\hline 3 & 58 & & & & & & \\
\hline \multicolumn{8}{|c|}{ Histological grade } \\
\hline 1 & 28 & 16.318 & $1.571-169.479$ & 0.019 & 0.774 & $0.539-1.113$ & 0.167 \\
\hline 2 & 88 & & & & & & \\
\hline 3 & 51 & & & & & & \\
\hline \multicolumn{8}{|l|}{ Tumor size } \\
\hline $\mathrm{T} 1$ & 66 & 0.327 & $0.327-6.331$ & 0.630 & 0.799 & $0.571-1.117$ & 0.190 \\
\hline $\mathrm{T} 2$ & 97 & & & & & & \\
\hline $\mathrm{T} 3$ & 4 & & & & & & \\
\hline \multicolumn{8}{|c|}{ LN metastasis } \\
\hline N0 & 92 & 3.140 & $1.255-7.857$ & 0.014 & 1.218 & $0.986-1.505$ & 0.068 \\
\hline N1 & 44 & & & & & & \\
\hline $\mathrm{N} 2$ & 20 & & & & & & \\
\hline N3 & 11 & & & & & & \\
\hline \multicolumn{8}{|l|}{ ER } \\
\hline Negative & 63 & 0.041 & $0.003-0.549$ & 0.016 & 0.516 & $0.312-0.854$ & 0.010 \\
\hline Positive & 104 & & & & & & \\
\hline \multicolumn{8}{|l|}{ PR } \\
\hline Negative & 95 & 6.908 & $0.552-86.498$ & 0.134 & 0.820 & $0.526-1.277$ & 0.379 \\
\hline Positive & 72 & & & & & & \\
\hline \multicolumn{8}{|l|}{ HER-2 } \\
\hline Negative & 122 & 0.940 & $0.177-4.995$ & 0.940 & 0.882 & $0.581-1.340$ & 0.557 \\
\hline Positive & 45 & & & & & & \\
\hline \multicolumn{8}{|l|}{ EGFR } \\
\hline Negative & 141 & 0.000 & 0.000 & 0.983 & 0.663 & $0.382-1.151$ & 0.144 \\
\hline Positive & 26 & & & & & & \\
\hline \multicolumn{8}{|l|}{ CK 5/6 } \\
\hline Negative & 156 & 0.001 & 0.000 & 0.993 & 1.476 & $0.672-3.242$ & 0.333 \\
\hline Positive & 11 & & & & & & \\
\hline \multicolumn{8}{|l|}{$\mathrm{Ki}-67, \%$} \\
\hline Low $(<10)$ & 123 & 7.922 & $0.460-136.514$ & 0.154 & 1.345 & $0.891-2.030$ & 0.158 \\
\hline $\operatorname{High}(\geq 10)$ & 44 & & & & & & \\
\hline \multicolumn{8}{|l|}{ IGF-1R } \\
\hline Low $(0,1)$ & 104 & 1.093 & $0.176-6.795$ & 0.924 & 0.928 & $0.637-1.353$ & 0.698 \\
\hline $\operatorname{High}(2,3)$ & 63 & & & & & & \\
\hline
\end{tabular}

RR, relative risk; CI, confidence interval; LN, lymph node; ER, estrogen receptor; PR, progesterone receptor; HER-2, human epidermal growth factor receptor 2; EGFR, epidermal growth factor receptor; CK, cytokeratin; IGF-1R, insulin-like growth factor 1 receptor.

In this study, the BI-RADS classification, which is widely in use today, was adopted for analyzing mammographic density. Although this is a semi-quantitative method, rather than a quantitative measurement, similar to the computer-assisted breast density assessment, it has been found to be close to a quantitative method, exhibiting high consistency rates in 

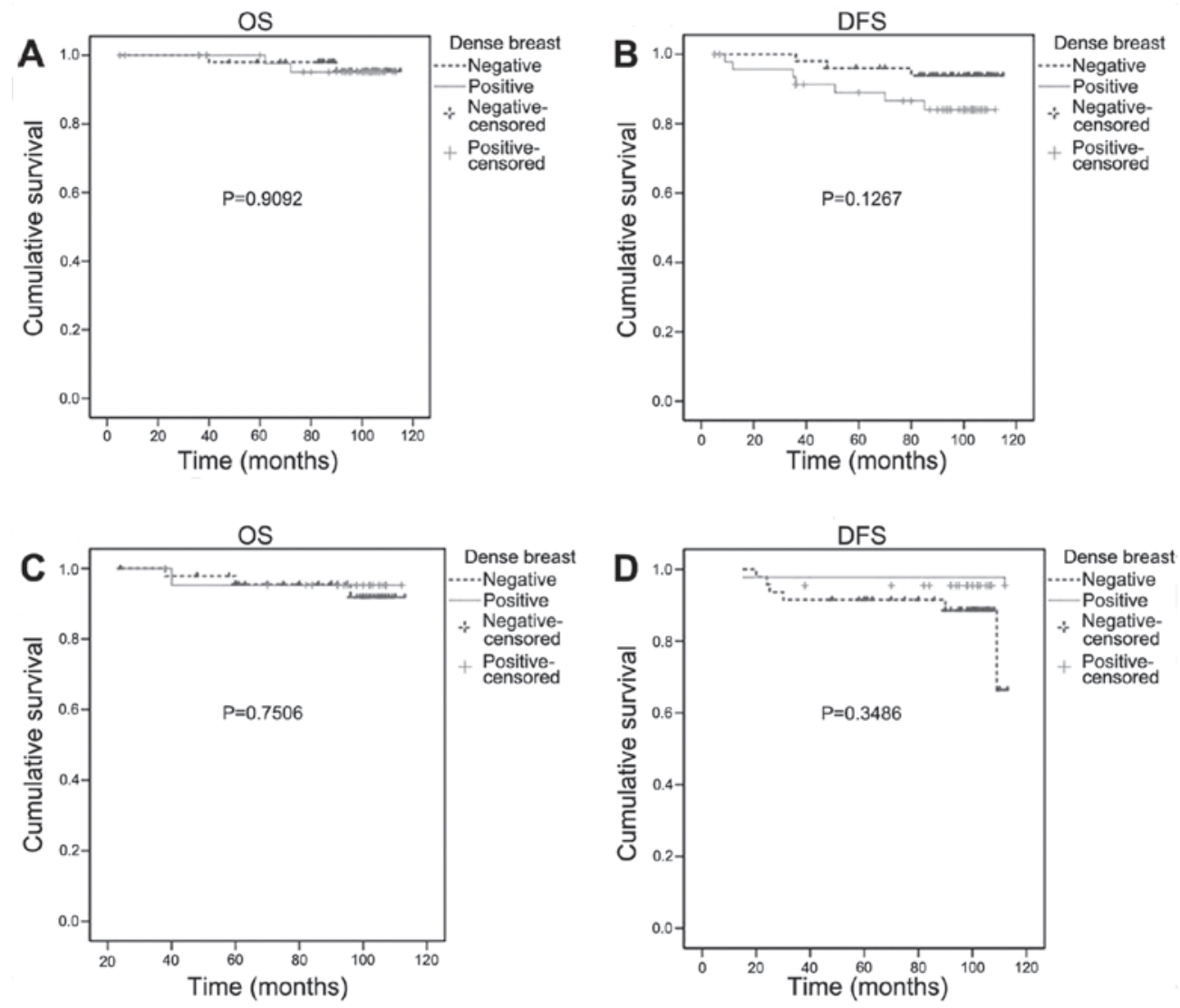

Figure 3. (A) Overall survival (OS), (B) disease-free survival (DFS) in premenopausal women and (C) OS, (D) DFS in postmenopausal women according to the breast density.
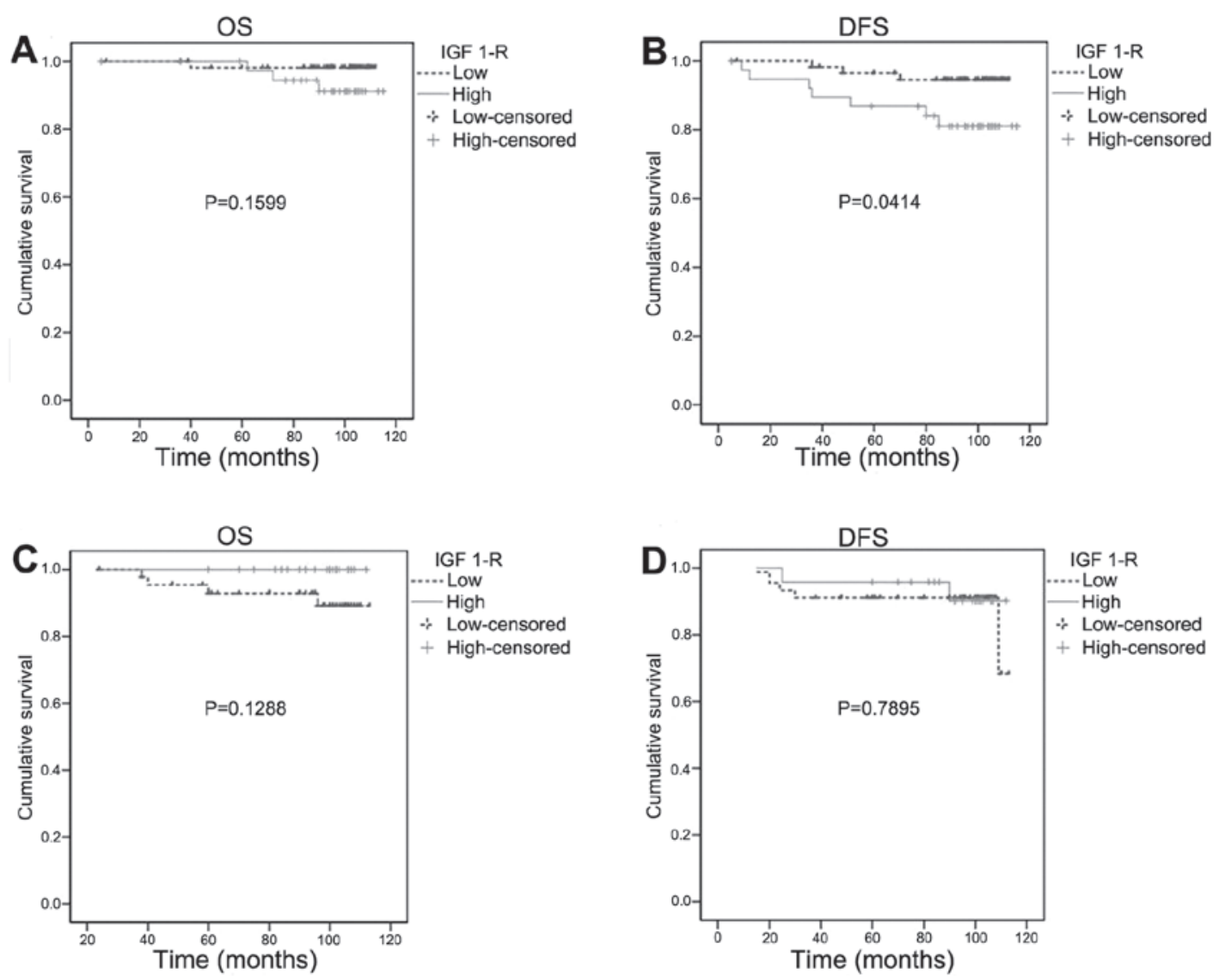

Figure 4. (A) Overall survival (OS), (B) disease-free survival (DFS) in premenopausal women and (C) OS, (D) DFS in postmenopausal women according to insulin-like growth factor 1 receptor (IGF-1R) overexpression. 
terms of intra- and inter-observer variability. According to comparative studies on different mammographic readings, no significant difference was found between the BI-RADS-based group and the other group using computer-based calculation of absolute areas in terms of several clinicopathological factors $(21,22)$. In view of mammographic timing, screening at a certain point in time during the menstrual cycle possibly ensures a more accurate measurement of density; however, in the majority of the cases, density does not vary significantly depending on different points of time during the menstrual cycle. The reason for reading the tumour-free parts is to avoid having the reading affected by the radio-opacity of most tumours. Assessing the density of one breast only instead of both sides may lower the accuracy of the density measurement, although the high consistency in density between the two breasts prevents against wrongful density classification $(4,23)$.

The univariate analysis identified factors such as age, BMI, menopausal status and histological grade as relevant to dense breast tissue, whereas the multivariate analysis demonstrated the relevance of age and histological grade. In this study, the univariate analysis demonstrated that dense breast tissue was a more frequent finding in pre- rather than postmenopausal women, whereas the multivariate analysis found no such relevance, suggesting that age rather than menopausal status is more significant. In terms of BMI, the univariate analysis identified an inverse correlation between increased BMI and frequency of dense breast tissue, whereas the multivariate analysis demonstrated no significant correlation. Age was found to be inversely correlated with dense breast tissue. In an autopsy study by Li et al (24), density was found to be high when cell nuclei occupied large areas, whereas nuclear grade was not found to be associated with dense breast tissue in the present study. However, histological grade was found to be related to increased breast tissue density, which requires further investigation. It was reported that ER-positive compared to negative tumours were more frequently associated with dense breast tissue. By contrast, breast tissue density was not associated with the expression of ER in the present study, which is consistent with the findings of with Ghosh et al (22). This study reported that the overexpression of IGF-1R may be significantly associated with dense breast tissue on mammography.

IGF-1 in the blood is considered to be an important factor affecting breast tissue density. Anti-estrogens administered to patients with high IGF-1 in the blood reduced IGF-1 levels and breast tissue density, indicating that IGF-1 affects breast density $(25,26)$. The concentration of IGF-1 in the blood, as well as breast density, is known to decrease with age. However, dense breast tissue becomes less frequent with age, while the incidence of breast cancer gradually increases, indicating that other factors may be involved. To assess the relevance to breast tissue density more accurately, it is crucial to investigate the expression of IGF-1R in tissues in lieu of IGF-1 in the blood, on which no study results have been reported thus far. The concentration of IGF-1 in the blood is known to decrease with age, whereas IGF-1R overexpression in this study was found to increase up to the age of 40 years and decrease thereafter, indicating differences from the expression in actual cancer tissues. As regards age, IGF-1R overexpression was found in women in their 4th and 5th decades of life, which represents a similar distribution in the age groups prone to breast cancer among Korean women. The present study found that the overexpression of IGF-1R in the breast cancer tissues of women aged $\geq 40$ years was associated with the presence of dense breast tissue on mammography. Based on this finding, IGF-1R overexpression appears to play an important role in breast cancer patients with dense breast tissue. Based on reports that IGF-1 and IGF-1R expression varies across ethnic groups, ethnicity-based correlations between dense breast tissue and IGF-1R overexpression should be investigated, in order to elucidate the effect of IGF-1R overexpression on breast cancer patients with dense breast tissue $(27,28)$.

IGF-1R is associated with several types of cancer, including breast and prostate cancer. The signaling stages of IGF-1R are crucial for the normal development of mammary tissues and play an important role in mitosis and anti-apoptosis. The self-phosphorylation of IGF-1R, the phosphorylation of insulin receptor substrates (IRS) 1-4 by tyrosine kinase and the activation of phosphoinositide 3-kinase (PI3K)/Akt/mammalian target of rapamycin (mTOR) signaling system play important roles in the differentiation and survival of tumour cells (29). To determine IGF-1R expression and the mechanism underlying its effects, it is necessary to examine the IRS that function as a signaling system of IGF-1R, SHC (leading to Ras/Raf/mitogen activated protein kinase cascade) and PI3K, along with the expression of downstream signaling molecules, such as mTOR, activated by PI3K. Recently, IGF-1R overexpression was reported to contribute to resistance to tamoxifen, chemotherapy, Herceptin and radiotherapy. Therefore, it is necessary to predict the resistance to treatment of a mammographically dense breast and investigate the administration of agents to manage resistant cases $(30,31)$.

As regards the expression of IGF-1R as a prognostic factor, Kim et al (17) reported that, in Korean breast cancer patients, IGF-1R expression was associated with high DFS $(\mathrm{P}=0.026)$ and 5-year survival rates $(\mathrm{P}=0.019)$, which were favourable prognostic factors. This finding was attributable to the correlation of IGF-1R overexpression to ER-positive and HER-2-negative tumours, which was considered as a good prognostic factor. By contrast, the present study found no correlation with ER status (12). Similar to the results of Shimizu et al (15) there was no observed correlation with age, tumour size, lymph node metastasis, histological grade, hormone receptor status and OS rates in this study. The present study found no factors associated with the relevance between IGF-1R, clinicopathological characteristics and biomarkers, in agreement with the results of Taunk et al (32), who reported that, in a group without lymph node metastasis, IGF-1R overexpression was associated with low survival rates. By contrast, the present study found no effect of IGF-1R overexpression on OS rates, irrespective of lymph node metastasis.

The overexpression of IGF-1R in premenopausal women was found to be relevant to HER-2 positivity with low DFS, indicating that IGF-1R overexpression in premenopausal women may represent an unfavorable prognostic factor. In the subgroup analysis based on the overexpression of IGF-1R and the presence/absence of dense breast tissue, the concomitant occurrence of IGF-1R overexpression and dense breast tissue in premenopausal women was associated with a lower DFS $(\mathrm{P}=0.0154)$ and may be considered as an unfavorable prognostic factor compared to those with no such concomitant characteristics. Several recent studies reported 
IGF-1R overexpression to be an unfavorable prognostic factor, but the results were inconsistent, which warrants further investigation $(15,17,18,32,33)$. ER $(\mathrm{P}=0.010)$ was the factor found to affect patients' DFS rate, whereas nuclear grade $(\mathrm{P}=0.029)$, histological grade $(\mathrm{P}=0.019), \mathrm{ER}(\mathrm{P}=0.016)$ and lymph node metastasis $(\mathrm{P}=0.014)$ were associated with $\mathrm{OS}$, which is in agreement with the common prognostic factors of breast cancer. Survival rates did not vary according to tumour subtypes. The present study investigated the frequency of IGF-1R overexpression in breast cancer tissues and the frequency of mammographic dense breast tissue, in order to analyze the correlations between the two. Further studies are required investigating IGF-1R expression in reference to density of normal breast tissues as well as cancer tissues, in order to elucidate the effect of IGF-1R on breast density.

In conclusion, IGF-1R expression in breast cancer tissue was found to be significantly associated with mammographic breast density in patients aged $>40$ years. It appears that IGF-1R expression in breast cancer plays an important role in cases with dense breast tissue. In premenopausal women, IGF-1R overexpression in breast cancer tissue was significantly associated with HER-2 positivity and poor DFS. However, IGF-1R overexpression in this study exhibited no correlation with other clinicopathological parameters. Dense breast tissue was found to be associated with age and histological grade. There was no difference in DFS and OS according to breast density.

\section{References}

1. Couzin J: Breast cancer. Dissecting a hidden breast cancer risk. Science 309: 1664-1666, 2005.

2. Ursin G, Ma H, Wu AH, Bernstein L, Salane M, Parisky YR, Astrahan M, Siozon CC and Pike MC: Mammographic density and breast cancer in three ethnic groups. Cancer Epidemiol Biomarkers Prev 12: 332-338, 2003.

3. Maskarinec G, Pagano I, Lurie G, Wilkens LR and Kolonel LN: Mammographic density and breast cancer risk: The multiethnic cohort study. Am J Epidemiol 162: 743-752, 2005.

4. Diorio C, Pollak M, Byrne C, Mâsse B, Hébert-Croteau N, Yaffe M, Coté G, Bérubé S, Morin C and Brisson J: Insulin-like growth factor-I, IGF-binding protein-3, and mammographic breast density. Cancer Epidemiol Biomarkers Prev 14: 1065-1073, 2005.

5. Bremnes Y, Ursin G, Bjurstam N, Rinaldi S, Kaaks R and Gram IT: Insulin-like growth factor and mammographic density in postmenopausal Norwegian women. Cancer Epidemiol Biomarkers Prev 16: 57-62, 2007.

6. Grimberg A and Cohen P: Role of insulin-like growth factors and their binding proteins in growth control and carcinogenesis. J Cell Physiol 183: 1-9, 2000.

7. Guo YP, Martin LJ, Hanna W, Banerjee D, Miller N, Fishell E, Khokha R and Boyd NF: Growth factors and stromal matrix proteins associated with mammographic densities. Cancer Epidemiol Biomarkers Prev 10: 243-248, 2001.

8. Sarfstein R, Maor S, Reizner N, Abramovitch S and Werner H: Transcriptional regulation of the insulin-like growth factor-I receptor gene in breast cancer. Mol Cell Endocrinol 252: 241-246, 2006.

9. Miller BS and Yee D: Type I insulin-like growth factor receptor as a therapeutic target in cancer. Cancer Res 65: 10123-10127, 2005.

10. Hartog H, Wesseling J, Boezen HM and van der Graaf WT: The insulin-like growth factor 1 receptor in cancer: Old focus, new future. Eur J Cancer 43: 1895-1904, 2007.

11. Happerfield LC, Miles DW, Barnes DM, Thomsen LL, Smith P and Hanby A: The localization of the insulin-like growth factor receptor 1 (IGFR-1) in benign and malignant breast tissue. J Pathol 183: 412-417, 1997.

12. Bhargava R, Beriwal S, McManus K and Dabbs DJ: Insulin-like growth factor receptor-1 (IGF-1R) expression in normal breast, proliferative breast lesions, and breast carcinoma. Appl Immunohistochem Mol Morphol 19: 218-225, 2011.
13. Ouban A, Muraca P, Yeatman T and Coppola D: Expression and distribution of insulin-like growth factor-1 receptor in human carcinomas. Hum Pathol 34: 803-808, 2003.

14. Yanochko GM and Eckhart W: Type I insulin-like growth factor receptor over-expression induces proliferation and anti-apoptotic signaling in a three-dimensional culture model of breast epithelial cells. Breast Cancer Res 8: R18, 2006.

15. Shimizu C, Hasegawa T, Tani Y, Takahashi F, Takeuchi M, Watanabe T, Ando M, Katsumata N and Fujiwara Y: Expression of insulin-like growth factor 1 receptor in primary breast cancer: Immunohistochemical analysis. Hum Pathol 35: 1537-1542, 2004.

16. Chong YM, Williams SL, Elkak A, Sharma AK and Mokbel K: Insulin-like growth factor 1 (IGF-1) and its receptor mRNA levels in breast cancer and adjacent non-neoplastic tissue. Anticancer Res 26: 167-173, 2006.

17. Kim JH, Cho YH, Park YL, Sohn JH and Kim HS: Prognostic significance of insulin growth factor-I receptor and insulin growth factor binding protein-3 expression in primary breast cancer. Oncol Rep 23: 989-995, 2010.

18. Creighton CJ, Casa A, Lazard Z, Huang S, Tsimelzon A, Hilsenbeck SG, Osborne CK and Lee AV: Insulin-like growth factor-I activates gene transcription programs strongly associated with poor breast cancer prognosis. J Clin Oncol 26: 4078-4085, 2008.

19. Bock K, Hadji P, Duda VF, Jackisch C and Wagner U: Mammographic breast density and breast cancer risk during HRT. Zentralbl Gynakol 127: 217-221, 2005 (In German).

20. Martin LJ, Minkin S and Boyd NF: Hormone therapy, mammographic density, and breast cancer risk. Maturitas 64: 20-26, 2009.

21. Ding J, Warren R, Girling A, Thompson D and Easton D: Mammographic density, estrogen receptor status and other breast cancer tumor characteristics. Breast J 16: 279-289, 2010.

22. Ghosh K, Brandt KR, Sellers TA, Reynolds C, Scott CG, Maloney SD, Carston MJ, Pankratz VS and Vachon CM: Association of mammographic density with the pathology of subsequent breast cancer among postmenopausal women. Cancer Epidemiol Biomarkers Prev 17: 872-879, 2008.

23. Harvey JA and Bovbjerg VE: Quantitative assessment of mammographic breast density: Relationship with breast cancer risk. Radiology 230: 29-41, 2004.

24. Li T, Sun L, Miller N, Nicklee T, Woo J, Hulse-Smith L, Tsao MS Khokha R, Martin L and Boyd N: The association of measured breast tissue characteristics with mammographic density and other risk factors for breast cancer. Cancer Epidemiol Biomarkers Prev 14: 343-349, 2005.

25. Pollak M: IGF-I physiology and breast cancer. Recent Results Cancer Res 152: 63-70, 1998.

26. Meggiorini ML, Labi L, Vestri AR, Porfiri LM, Savelli S and De Felice C: Tamoxifen in women with breast cancer and mammographic density. Eur J Gynaecol Oncol 29: 598-601, 2008.

27. Pinheiro SP, Holmes MD, Pollak MN, Barbieri RL and Hankinson SE: Racial differences in premenopausal endogenous hormones. Cancer Epidemiol Biomarkers Prev 14: 2147-2153, 2005.

28. Kalla Singh S, Tan QW, Brito C, De León M and De León D: Insulin-like growth factors I and II receptors in the breast cancer survival disparity among African-American women. Growth Horm IGF Res 20: 245-254, 2010.

29. Rozengurt E, Sinnett-Smith J and Kisfalvi K: Crosstalk between insulin/insulin-like growth factor-1 receptors and $\mathrm{G}$ protein-coupled receptor signaling systems: A novel target for the antidiabetic drug metformin in pancreatic cancer. Clin Cancer Res 16: 2505-2511, 2010.

30. Nahta R, Yuan LX, Zhang B, Kobayashi R and Esteva FJ: Insulin-like growth factor-I receptor/human epidermal growth factor receptor 2 heterodimerization contributes to trastuzumab resistance of breast cancer cells. Cancer Res 65: 11118-11128, 2005.

31. Chong K, Subramanian A, Sharma A and Mokbel K: Measuring IGF-1, ER- $\alpha$ and EGFR expression can predict tamoxifen-resistance in ER-positive breast cancer. Anticancer Res 31: 23-32, 2011.

32. Taunk NK, Goyal S, Moran MS, Yang Q, Parikh R and Haffty BG: Prognostic significance of IGF-1R expression in patients treated with breast-conserving surgery and radiation therapy. Radiother Oncol 96: 204-208, 2010.

33. Kostopoulos I, Arapantoni-Dadioti P, Gogas H, et al: Evaluation of the prognostic value of HER-2 and VEGF in breast cancer patients participating in a randomized study with dose-dense sequential adjuvant chemotherapy. Breast Cancer Res Treat 96: 251-261, 2006. 